\title{
The Control of Pranic Energy through Breathing Ratios in the Process of Giving Birth
}

Volume 5 Issue 5 - 2017

\section{Opinion}

Yoga is undoubtedly the science of breathing. From its ancient scriptures to the most recent researches breathing and prana intake have always been matters of discussion and conflict. The control of breath has been a secret weapon when a woman goes in to labour and Yogic breathing (Pranayama) covers almost every aspect of the motion of energy while our feminine bodies try to give birth. Labour's pain anagement is one of the most difficult issues in midwifery and part of a series of courses for parentsto-be (psychoprophylaxis method). However, when it comes to yogic terms, the art of breathing (pranayama techniques) is only a way to change the way that the energy circulates into our energy channels (nadis) and through the energy stations (chakras). Our body is compiled by many energy channels united with each other in certain energy stations which we call chakras and are considered as the main energy points that can assemble prana and rotate it in order to sustain our normal levels of energetic status.

Through our breath a great amount of energy comes in to the body and is being distributed through the nadis to our etheric body. In the chakras' rotation it flushes out toxins and energy blockages and continues to move through the pranic circulation to the physical organs and backwards to the chakras-nadis system. According to the yogic science in order to accumulate prana, the inhalation has to be followed by an internal pause of breath and the exhalation has to be followed by an external pause. This constitutes a four-stage breathing which can influence our etheric plane, otherwise it would be just a simple exchange of $\mathrm{O}_{2}-\mathrm{CO}_{2}$, with a minor effect on our energy levels.

During labour, our prana has the tendency to create a downward movement enhancing the apana energy which is the one that controls the elimination of fluids and the extraction of the fetus. We need the apana energy to create contractions to the uterus and we need a sattvic (balanced) movement of prana in apana's nadis, so as these contractions can be effective and can really help the baby to be born. All the mind movements (thoughts, emotions, etc) can create a reverse movement so it is very important that the pregnant woman can regulate her breathing so she can immediately correct the unwanted alterations. This means that she has to be aware of her body and mind situation and at this point the practice of meditation and mindfulness is very important.

The four-stage-breathing can be used in various ratios in order to achieve multiple results. For the best effect in birthing progress an ideal ratio would be 1:1:2:1. In simple words one could say that when a contraction begins the woman should take a deep inhalation of 3 $\mathrm{sec}$, hold her breath for $3 \mathrm{sec}$, exhale for 6 and pause for $3 \mathrm{sec}$ again. This depending on her lung capacity can be 4-4-8-4, 5-5-10-5, etc. The important thing is to hold the ratio. In this way the prana intake can grow the size of chakras during the in-pause and with the double exhalation the flushing out of toxins through the lower chakras will stimulate the apana. Holding an external pause will help the chakras

\author{
Giannakopoulou Aikaterini \\ Midwife and Yoga teacher, Greece
}

Correspondence: Giannakopoulou Aikaterini, Midwife and Yoga teacher (Full Member of International Yoga Teachers Association), Pranic Healing Instructor, Greece, Email aikaterinigiann@gmail.com

Received: December 232016 | Published: March 03, 2017

decrease in size again so that the energy body is not overwhelmed by energy during partus. This ratio can accelerate the birthing process only by regulating the contractions and by gaining their best pranic effect of pranic power to the uterus.

Another ratio can be 2-1-2-1, helping the etheric body create a bigger energy space in and out of the woman's body. Especially when a woman or a uterus is tired and there is a lack of coordination of oxytocin hormone and its uterine receptors, this ratio can rehabilitate and reestablish their connection. This is also a very good breathing pattern in the beginning of labour, in what we call inactive phase, as it helps the childbirth become active. It can also be used in long and strenuous deliveries or in cases with uterus atoni.

The best part of using pranayama in labour is that these breathing pauses help the mind concentrate and the body relaxes as they create a safer environment for the mother and the baby to work together. Moreover, they have a great effect to the child's heart frequency and its overall energetic status. One can say that the ratios contribute to a more conscious birth, a more aware state of giving birth, a closer connection to our spiritual self and its capability to control the prana and its outcomes in our physical and etheric bodies. Yoga exercises, relaxation and meditative techniques can supplement this magic work of nature that we call natural birth.

\section{Acknowledgments}

None.

\section{Conflicts of Interest}

None.

\section{Funding}

None. 